\title{
Arterial counterpulsation in continuing myocardial ischaemia after acute myocardial infarction
}

\author{
NEVILLE L. SAMMEL AND MICHAEL F. O'ROURKE \\ From the Department of Medicine, University of N.S.W., and St. Vincent's Hospital, Sydney, \\ N.S.W., Australia
}

SUMMARY Twenty-six patients underwent arterial counterpulsation for refractory heart failure without shock complicating acute myocardial infarction. Patients were divided into a group of 12 with continuing myocardial ischaemia, evidenced by anginal pain associated with abnormal ST segment elevation, and a group of 14 without continuing ischaemia. Clinical features (apart from pain) and prognostic indices were similar in the two groups when counterpulsation was started but short- and long-term results were different.

Hospital survival was 92 per cent (11/12) and 43 per cent (6/14), respectively, in the groups with and without ischaemia and four-year survival was 73 per cent and 7 per cent. Counterpulsation is of greatest value in acute infarction when used to relieve myocardial ischaemia.

While arterial counterpulsation has been used widely and increasingly over the past eight years in patients with acute coronary artery disease, there is still no consensus as to how it can be applied most effectively. Apart from use in surgical patients, the principal application has been at the two extreme ends of the spectrum of acute infarction-in patients with cardiogenic shock on the one hand (Dunkman et al., 1972; Scheidt et al., 1973; Jackson et al., 1977) and in patients with threatening infarction or coronary insufficiency on the other (Mundth, 1976; Leinbach et al., 1978). Despite the use of counterpulsation, mortality rate has remained high in cardiogenic shock and low in coronary insufficiency. No controlled trials have been reported and it is disputed that counterpulsation offers any advantage over conventional treatment in either condition (Forrester et al., 1976; Kuhn, 1976; O'Rourke, 1977).

Counterpulsation has been shown in animals (Goldfarb, 1969; Powell et al., 1970; Maroko et al., 1972) and in man (Mueller et al., 1971; Maroko et al., 1972) to provide substantial relief of myocardial ischaemia, through reduction in ventricular afterload and increase in myocardial perfusion. The animal experimental studies have confirmed that counterpulsation can reduce infarct size and improve survival when initiated at a time when reversible ischaemia is still in evidence.

It has been suggested (Scheidt et al., 1973;

Received for publication 12 March 1979
O'Rourke et al., 1975) that indifferent results of counterpulsation in patients with acute infarction are the result of it being initiated so late after onset of symptoms, that myocardial ischaemic damage has become irreversible. In order to test this theory, we reviewed results of patients undergoing counterpulsation for refractory heart failure without shock after acute infarction. Patients in cardiogenic shock were excluded because clouded consciousness in the majority prevented accurate interpretation of chest pain; in addition we wished to eliminate the haemodynamic and metabolic effects of shock itself (Page et al., 1971; Mueller and Ayres, 1974).

\section{Patients}

During the six-year period to December 1977, 26 patients with acute infarction underwent counterpulsation for refractory heart failure without shock, using the Avco intra-aortic balloon system. During the same period, 86 patients with cardiogenic shock were treated with counterpulsation.

All 26 patients had clinical, electrocardiographic, and enzymatic evidence of acute infarction by WHO criteria. All had severe and persistent cardiac failure despite conventional medical treatment.

Twelve patients were considered to have continuing ischaemia on the basis of persistent anginal pain unresponsive to glyceryl trinitrate, together with abnormal ST segment elevation in electrocardiographic leads showing the infarct pattern: these comprised group 1. The other 14 patients did 
not have continuing ischaemic chest pain at the time counterpulsation was started: these comprised group 2.

Clinical features of patients in the two groups were similar (Table).

Prognostic indices (Peel et al., 1962; Norris et al., 1969) predicted survival rates less than 50 per cent in both groups. The only significant difference was the time between onset of symptoms and introduction of counterpulsation, which averaged 26 hours (median 19 hours) in group 1 and 155 hours (median 57 hours) in group 2.

Patients were monitored through the period of counterpulsation with direct measurement of pulmonary artery and brachial or radial artery pressure. Counterpulsation was continued for one to 15 (mean 7.5) days, the duration being determined by death or the time required for maximal sustained improvement (O'Rourke et al., 1979). One patient in group 1 underwent coronary artery bypass grafting when anginal pain recurred after termination of counterpulsation. Three patients in group 2 underwent coronary artery bypass grafting during the period of counterpulsation because of continuing

Table Patients with severe refractory heart failure complicating acute myocardial infarction

\begin{tabular}{|c|c|c|}
\hline & $\begin{array}{l}\text { Continuing } \\
\text { ischaemia } \\
\text { (group 1) }\end{array}$ & $\begin{array}{l}\text { No ischaemia } \\
\text { (group 2) }\end{array}$ \\
\hline Number & 12 & 14 \\
\hline Previous infarction & 4 & 4 \\
\hline Age (y) & 51 & 55 \\
\hline \multicolumn{3}{|l|}{ Prognostic indices } \\
\hline Peel & $\overline{19 \cdot 5}$ & $\overline{20 \cdot 5}$ \\
\hline Norris & $\overline{9 \cdot 8}$ & $\overline{10 \cdot 8}$ \\
\hline Peak CK level (IU/1)* & $1776 \pm 1309$ & $1858 \pm 1314$ \\
\hline \multicolumn{3}{|c|}{ Onset symptoms $\rightarrow \mathrm{CP}$ (hours) } \\
\hline Median & 19 & 57 \\
\hline Range & $5-72$ & $8-456$ \\
\hline \multicolumn{3}{|l|}{ Arterial pressure (mmHg) } \\
\hline$\therefore$ (before CP) & $\overline{116 / 72}$ & $\overline{106 / 76}$ \\
\hline - (after 24 hours CP) & $\overline{75 / 109}$ & $\overline{79 / 103}$ \\
\hline (at termination of $\mathrm{CP}$ ) & $\overline{108 / 72}$ & $\overline{102 / 72}$ \\
\hline \multicolumn{3}{|l|}{ Heart rate } \\
\hline (before CP) & $\overline{119} \pm 13 S D$ & $\overline{117} \pm 18$ \\
\hline (after 24 hours CP) & $\overline{101} \pm 14$ & $\overline{107} \pm 18$ \\
\hline (at termination of $\mathrm{CP}$ ) & $\overline{81} \pm 10$ & $\overline{101} \pm 9$ \\
\hline \multicolumn{3}{|c|}{ Pulmonary artery pressure (mmHg) } \\
\hline (before CP) & $\overline{33} \pm 7$ & $\overline{31} \pm 8$ \\
\hline (after 24 hours CP) & $\overline{18} \pm 5$ & $\overline{20} \pm 7$ \\
\hline (at termination of $\mathrm{CP}$ ) & $\overline{12} \pm 3$ & $\overline{16} \pm 4$ \\
\hline Duration of CP (days) & $\overline{8.9}$ & $\overline{6 \cdot 3}$ \\
\hline
\end{tabular}

* Normal upper level of normal $40 \mathrm{IU} / 1$.

CP, counterpulsation. heart failure or arrhythmias; all these patients died in hospital. One patient in group 2 had repair of acute ventricular aneurysm; this patient is still living and the only one in group 2 not to be disabled subsequently.

All hospital survivors were reviewed periodically after discharge, with interview and examination performed by one of us; functional status was assessed according to the New York Heart Association criteria. Follow-up period was one to 56 (mean 33) months. No patient was lost to follow-up.

\section{Results}

While all patients showed improvement with initiation of counterpulsation, this was more prompt, more distinct, and more sustained in the patients with continuing ischaemia. The effect on ischaemic pain was quite dramatic, this being abolished within minutes in 11 patients and within 12 hours in the other. Cardiac failure was eased in all patients, but the most obvious benefit (reflected in change of pulmonary artery pressure and heart rate (Table)) was seen in group 1 patients.

Of the 12 patients in group 1 there was only one hospital death-from low output cardiac failure 27 days after termination of counterpulsation. Of the 14 patients in group 2 there were eight hospital deaths-three from late ventricular fibrillation and five from cardiac failure. Difference in hospital survival $(92 \%$ in group $1,43 \%$ in group 2$)$ was statistically significant $(P<0.01)$.

Two of the 11 hospital survivors in group 1 and four of the six in group 2 died during the follow-up period. One died suddenly, two after reinfarction, and three from chronic cardiac failure. Survival rate at four years (Fig.) was 73 per cent in group 1 and 7 per cent in group $2(P<0.005)$.

Of the nine patients in group 1 who were alive at follow-up, six were in NYHA functional class 1 or 2 . There were only two survivors at follow-up in group 2, and only one in functional class 1 or 2; this patient had undergone repair of ventricular aneurysm in association with counterpulsation.

\section{Discussion}

The patients presented here had a poor prognosis with continuation of conventional treatment. The group without evidence of continuing ischaemia had a hospital mortality close to that predicted from prognostic indices $(57 \%$ observed of $50 \%$ predicted by Peel and Norris indices), and high late mortality after hospital discharge. Counterpulsation does not appear to have helped these patients. In contrast, counterpulsation appears to have substantially 


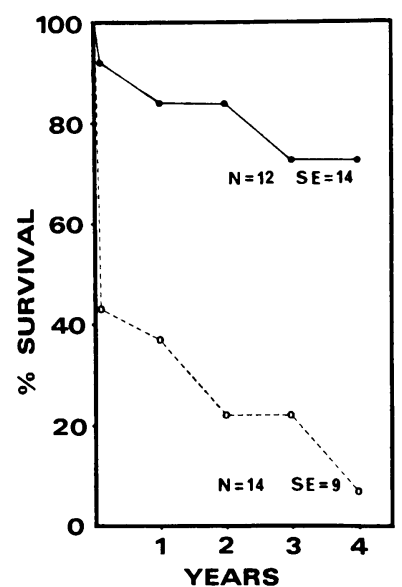

Fig. Life table: unbroken line: patients with continuing myocardial ischaemia at initiation of counterpulsation (group 1), broken line: patients without continuing myocardial ischaemia at initiation of counterpulsation (group 2). Significance at four years, $P<0.005$.

improved the outlook of patients with persistent myocardial ischaemia; in these, hospital mortality, late mortality, and late morbidity were considerably better than in the group whose clinical features were essentially similar, except for the absence of myocardial ischaemia. The fact that improvement in morbidity and mortality was associated with prompt relief of anginal pain after counterpulsation was started suggests that such improvement resulted directly from relief of myocardial ischaemia and preservation of reversibly damaged muscle. This is what one might expect from theoretical considerations and animal experimental studies (Goldfarb, 1969; Powell et al., 1970; Mueller et al., 1971; Maroko et al., 1972).

Patients with continuing myocardial ischaemia underwent counterpulsation much earlier than those without continuing ischaemia, the median delay after onset of symptoms being 19 cf 57 hours. It is possible that this factor alone may have been more important than the presence of ischaemia in determining favourable outcome though this seems unlikely. In group 2, delay before onset of symptoms and counterpulsation was similar in those who died in hospital (median 53 hours) and in those who survived (median 61 hours). Further, in group 1, the one hospital death and the two late deaths occurred in patients undergoing counterpulsation early (seven hours, five hours, and 18 hours, respectively) after the onset of symptoms. Certainly results were very poor in patients who underwent counterpulsation more than four days after the onset of symptoms. (Of four such patients, there was only one survivor-and this patient required excision of acute ventricular aneurysm.) It is probable that myocardial ischaemia and delay after onset of symptoms are not independent determinants of survival in relation to use of counterpulsation, but that myocardial ischaemia is more likely to be present early rather that late after onset of symptoms. In other words, counterpulsation was most effective when applied early after onset of symptoms because there was usually more ischaemia and more reversible damage present at this time.

Results presented here support the view that counterpulsation is of greatest value in acute infarction when used early after onset of symptoms to relieve continuing myocardial ischaemia. We are currently testing this hypothesis in a ramdomised controlled trial.

\section{References}

Dunkman, W. B., Leinbach, R. C., Buckley, M. J., Mundth, E. D., Kantrowitz, A. R., Austen, W. C., and Saunders, C. (1972). Clinical and hemodynamic results of intra-aortic balloon pumping and surgery for cardiogenic shock. Circulation, 46, 465-477.

Forrester, J. S., Diamond, G., Chatterjee, K., and Swan, H. J. C. (1976). Medical therapy of acute myocardial infarction by application of hemodynamic subsets. Part II. New England fournal of Medicine, 295, 1404-1413.

Goldfarb, D. (1969). Mechanical circulatory assistance in the treatment of cardiac failure. Progress in Cardiovascular Diseases, 12, 221-242.

Jackson, G., Cullum, P., Pastellopoulous, A., Macarthur, H., and Jewitt, D. (1977). Intra-aortic balloon assistance in cardiogenic shock after myocardial infarction or cardiac surgery. British Heart fournal, 39, 598-604.

Kuhn, L. A. (1976). Intra-aortic balloon pumping in acute myocardial infarction. American fournal of Cardiology, 38, 668-669.

Leinbach, R. C., Gold, H. K., Harper, R. W., Buckley, M. J., and Austen, W. C. (1978). Early intra-aortic balloon pumping for anterior myocardial infarction without shock. Circulation, 58, 204-210.

Maroko, P. R., Bernstein, E. D., Libby, P., Delaria, G. A., Covell, J. W., Ross, J., jun, and Braunwald, E. (1972). Effects of intra aortic balloon counterpulsation on the severity of myocardial ischaemic injury following acute coronary occlusion. Circulation, 45, 1150-1159.

Mueller, H., and Ayres, S. M. (1974). Myocardial metabolism in shock following acute myocardial infarction. In Shock in Myocardial Infarction, ed R. Gunnar, H. Loeb, and S. Rahimtoola, pp. 173-207. Grune and Stratton, New York.

Mueller, H., Ayres, S. M., Conklin, E. F., Gianeill, S., Mazzara, J. T., Grace, W. T., and Nealon, T. F. (1971). The effects of intra-aortic counterpulsation on cardiac performance and metabolism in shock associated with acute myocardial infarction. Fournal of Clinical Investigation, 50, 1885-1900. 
Mundth, E. D. (1976). Mechanical and surgical interventions for the reduction of myocardial ischaemia. Circulation, 53 and 54, Suppl. I, 176-185.

Norris, R. M., Brandt, P. W. T., Caughey, D. E., Lee, A. J., and Scott, P. J. (1969). A new coronary prognostic index. Lancet, 1, 274-278.

O'Rourke, M. F. (1977). Arterial counterpulsation in the management of ischaemic heart disease. Australian and New Zealand fournal of Surgery, 47, 21-26.

O'Rourke, M. F., Chang, V. P., Windsor, H. M., Shanahan, M. X., Hickie, J. B., Morgan, J. H., Gunning, J. F., Seldon, R. W., Hall, G. V., Michell, G., Goldfarb, D., and Harrison, D. G. (1975). Acute severe cardiac failure complicating myocardial infarction: experience with 100 patients referred for consideration of mechanical left ventricular assistance. British Heart fournal, 37, 169-181.

O'Rourke, M. F., Sammel, N., and Chang, V. P. (1979). Arterial counterpulsation in severe refractory heart failure complicating acute myocardial infarction. British Heart fournal, 41, 308-316.

Page, D. L., Caulfield, J. B., Kastor, J. A., DeSanctis, R. W., and Sanders, C. A. (1971). Myocardial changes associated with cardiogenic shock. New England fournal of Medicine, 285, 133-137.
Peel, A. A. F., Semple, T., Wang, I., Lancaster, W. M., and Dall, J. L. G. (1962). A coronary prognostic index for grading the severity of infarction. British Heart fournal, 24, 745-760.

Powell, F. J., jun, Daggett, W. M., Magro, A. E., Bianco, J., Buckley, M. J., Saunders, C. A., Kantrowitz, A. R., and Austen, W. G. (1970). Effects of intra-aortic balloon counterpulsation on cardiac performance, oxygen consumption and coronary blood flow in dogs. Circulation Research, 26, 753764.

Scheidt, S., Wilner, G., Mueller, G., Summers, D., Lesch, M., Wolfe, G., Krakaver, J., Rugenfire, M., Fleming, P., Noon, G., Oldham, N., Killip, T., and Kantrowitz, A. (1973). Intra-aortic balloon counterpulsation in cardiogenic shock: report of a cooperative clinical trial. New England fournal of Medicine, 288, 979-984.

Requests for reprints to Dr Michael F. O'Rourke, Professorial Department of Medicine, St. Vincent's Hospital, Darlinghurst 2010, New South Wales, Australia. 